\title{
REFLEX BRADYCARDIA IN OPHTHALMIC AND OROPHARYNGEAL SURGERY*
}

\author{
F. A. WALTON, M.D.
}

A RECENT REPORT by Sorenson and Gilmore (1) has shown that during strabismus surgery cardiac irregularities, particularly bradycardia, occur frequently and may proceed to cardiac arrest. Irregularities (electrocardioscope and radial pulse control) occurred in sixteen out of seventeen consecutive cases. In fifteen patients the pulse, which was between 110 and 130, dropped with tension on the eye muscles (especially the medial rectus) to between 40 and 65 with an average of 49.4. Ventricular fibrillation occurred in one patient. The investigation was prompted by a case of cardiac arrest during traction on the medial rectus in a three-year-old child. This responded to rhythmic thumpeng on the chest. Further tension on the muscle reduced the heart rate to 40 (from 120). The operation was completed successfully with as little tension as possible on the muscle. The anaesthesia used for these patients was ether-oxygen. Premedication was codeine or methadon and atropine or scopolamine. Varying these premedicants had no effect on the arrhythmias, but atropine $1 / 150 \mathrm{gr}$. intravenously did control them. Hypoxia was probably not a factor in these cases as oxygen was the vehicle for the ether.

The authors point out that vagal tone reaches its peak during adolescence and early adulthood and that the occulo-cardiac reflex is positive in 90 per cent of children. They cite Aschner (2) who demonstrated by nerve sections in animals that the afferent limb of this reflex is the trigeminal nerve. Lyle (3) is also cited to the effect that all trigeminal nerve divisions carry sympathetic and parasympathetic components. Parasympathetic fibres, especially, are present in the ciliary ganglion and in the clliary nerves. Reid et al. (4) state that a healthy heart will never respond to vagal stimulation with serious symptoms, but anaesthesia renders the heart vulnerable to vagal stimulation by depression of the functional capacity of specific fibres in the myocardium.

In 1952 Papper and Howland (5) described bradycardia due to pressure on the eyeball by the head rest during cranial surgery uncler Pentothal $/ \mathrm{N}_{2} \mathrm{O}$ anaesthesia. They also describe two cases of reflex cardiac arrest from dural stimulation.

The paper by Sorenson and Gilmore has been ex ensively quoted and its importance and originality certainly deserve a wide audience. It serves as an introduction to the following observations over the past few years. My interest in this subject was first aroused in 1948 when I was called in to assist in the resuscitation of a girl of seven whose heart had stopped suddenly shortly after surgery had started on the internal rectus muscle of her second eye. Anaesthesia was ether insufflation and had been quite uneventful during the surgery on the first eye. A few drops of adrenaline had been instilled into the conjunctiva incision just prior to the arrest. The heart was not fibrillating, and intracardiac adrenalin,

'Presented at the Western Regional Meeting of the Canadian Anaesthetists' Society, Winnipeg, March 8, 1957.

$\nmid$ Roya_ Columbian Hospital, New Westminster, B C. 
artificial respiration with oxygen and cardiac massage for over two hours were unfortunately of no avail. Discussion at this time revealed that some time previously, in another hosp_tal, a child had died suddenly and unexpectedly while the head bandage was being applied at the completion of the operation. This first case was inexplicable at the time, although the adrenalin was naturally under suspicion. The effect of the atropine would be worn off by the time operation on the second eye was started. This was probably the most important factor. The second case could be explained by pressure on the eyeball by the bandages causing bradycardia and ultimately cardiac arrest.

\section{Clinical}

It was decided that the heart or the pulse would be monitored constantly in all eye operations, particularly in muscle operations on children. It was quite apparent that clearing or traction of eye muscles in children under ether $/ \mathrm{N}_{2} \mathrm{O} / \mathrm{O}_{2}$ ( $5 / 2$ litres per minute) anaesthesia frequently produces a bradycardia, especially when the internal rectus is being worked on. It was decided, therefore, to give d-tubo-curarine-chloride $1 \mathrm{cc}$. ( $3 \mathrm{mg}$.) or Flaxedil ${ }^{1} 1 \mathrm{cc}$. $(20 \mathrm{mg}$.) intramuscularly after induction and intubation, in order to reduce the amount of ether needed and also to relax the eye muscles. Adults and children from age six up were given an intravenous induction that included Demerol, Mecostrin ${ }^{2}$ or Flaxedil, and thiopentone followed by intubation and $\mathrm{N}_{2} \mathrm{O} / \mathrm{O}_{2}: 5 / 2$ litres per minute. Of twelve patients undergoing muscle operations (average age 10 years) -three with ether/$\mathrm{N}_{2} \mathrm{O}$ anaesthesia (two with intramuscular relaxant), nine with intravenous anaesthesia-only three showed any bradycardıa, and this was not marked. In a nineyear-old boy (intravenous anaesthetic) the pulse slowed from 110 to 88 or 80 on more than one occasion when the internal rectus was being cleared. The bradycardia was self limited. This boy had had his atropine (1/150 gr.) two hours previously instead of the usual 20-40 minutes preoperatively. Another (ether-OT\#2- $\mathrm{N}_{2} \mathrm{O}$ ), a two-year-old boy, had had only $1 / 250$ gr. of atropine and had not been given any curare or Flaxedil. His pulse dropped suddenly from 160 to 128 when pulling on the internal rectus; this was also self limited. The third, a two-and-a-half-year-old girl (ether- $\mathrm{N}_{2} \mathrm{O}$ ), had been given Demerol $15 \mathrm{mg}$. and Flaxedil $10 \mathrm{mg}$. intramuscularly, before starting the first eye. The pulse rose when clearing the medial rectus. Ether was used when the second eye was being done (during the second hour) and a bradycardia $160 \rightarrow 120$ occurred when traction was applied to the medial rectus. A man, age 27 , who had morphine gr. ${ }_{14}^{1 / 4}$ and scopolamine $1 / 150$ gr. preoperatively and a Demerol-Mecostrin-Pentothal $-\mathrm{N}_{2} \mathrm{O}$ anaesthetic had a transient bradycardia-from 60 to 50 with a blood pressure drop from 135 to 110 systolic each time each eye was pulled down forcibly to expose the superior rectus and superior oblique muscles. Other eye operations on adults, enucleation 7 , cataract removal 1 , iridectomy 4 , showed no bradycardia or drop in blood pressure. In fact, the blood pressure rose $15 \mathrm{~mm}$. $\mathrm{Hg}$ in two patients as the snare freed the eyeball and in another patient the

1Gallamine tri-ethodide.

2d-tubo curarine dimethyl ether chloride. 
pulse rate rose from 72 to 100 and the blood pressure rose 20 points when the internal rectus was being cleared. These patients all had intravenous anaesthesia including Demerol (preoperatively also), Mecostrin or Flaxedil and Pentothal/ $\mathrm{N}_{2} \mathrm{O}$.

More recently other causes of bradycardia in children have been noted. An extremely agitated girl of nine had to have an emergency oesophagoscopy. She was given atropine $1 / 150 \mathrm{gr}$. intramuscularly about 15 minutes preoperatively. The anaesthesia was Vinethene ${ }^{3}$ ether followed by endrotracheal $\mathrm{N}_{2} \mathrm{O} / \mathrm{O}_{2} 5 / 2$ litres per minute. She became pulseless on three occasions when the oesophagoscope was opposite the heart. This condition was relieved each time by withdrawing the scope. A similar situation occurred with a two-year-old boy having an oesophagoscopy. A five-year-old boy who had had rheumatic fever and had a heart murmur was having a tonsillectomy and adenoidectomy. The anaesthesia was Demerol $50 \mathrm{mg}$. Mecostrin 2\% mg.Pentothal 2 per cent 6 cc.-oxygen-\#3 orothracheal tube- $\mathrm{N}_{\mathrm{s}} \mathrm{O} 5 / 2$ litres per minute. His pulse slowed suddenly from 160 to 88 on three occasions while the adenoids and adenoid fossa were being dealt with. Reid (4) describes a patient who similarly developed cardiac arrest each time the adenoid fossa was stımulated. The reflex was controlled ultimately by intravenous atropine A girl of eight years who suffered from asthma and still had some rhonchi was given a Vinamar ${ }^{4}$-ether-orothracheal tube \#3- $\mathrm{N}_{2} \mathrm{O}$ anaesthetic. While a tonsil was being gullotined the pulse fell temporarily from 135140 to approximately 80 . A girl of 15 months was given a Vinamar-ether-orotracheal tube $\# 1-\mathrm{N}_{2} \mathrm{O}$ anaesthetic. Her pulse dropped suddenly from 160 to 115 when the doctor was pulling on the left tonsil. She had only had 1/300 gr of atropine and was "wet" as well. A relatively mild bradycardia has been noticed in two other patients undergoing tonsillectomies-one (aged 4) under ether; one under intravenous anaesthetic-and may have been present on other occasions as assisting at the operation does not allow one to monitor the pulse constantly. However, the boy who had had rheumatic fever probably had some cardiac damage and the girl with the asthma might well have had a vagal predominance. The third little girl was not well atropinized and had an ether anaesthetic. For several years now, we have been giving anaesthesia for dental fillings and extractions. The average age of these patients is five years. Generally speaking those five years or over are given an intravenous anaesthetic of Demerol-Mecostrin or FlaxedilPentothal- $\mathrm{O}_{2}$-intubation- $\mathrm{N}_{2} \mathrm{O}$, whlle the younger ones received a Vinethene or Vinamar ether induction followed by intubation and $\mathrm{N}_{2} \mathrm{O}$ with ether when needed. It was noted that the latter group often developed a bradycardia, for example, from 130 to 50 when drilling steadily without a pause. This bradycardia was easily terminated by stopping drilling for a few seconds. Bradycardıa did not occur when an intravenous anaesthetic as above was used; in fact, in some patients the pulse rate rose with persistent drilling, a pain effect. Latterly some smaller patients have been induced with rectal Pentothal (about $10 \mathrm{cc}$ of 2 per cent) and about twenty minutes later given Demerol (35-50 mg.) and Mecostrin

3D1-vinyl ether.

*Ethyl vinyl ether. 
(11/2-2 mg.) intramuscularly. About fifteen minutes later they are given Vinamar or ether inhalation, intubated and carried on $\mathrm{N}_{2} \mathrm{O} / \mathrm{O}_{2} 5 / 2$ litres. per minute. In these cases also no bradycardia occurs. Some of my colleagues use $\mathrm{N}_{2} \mathrm{O}$ and trilene after intubation and state that bradycardia does not occur, presumably because they use no more ether.

\section{Discussion}

A large experience with Demerol-Mecostrin- $\mathrm{N}_{2} \mathrm{O}$ anaesthesia (6) indicates that the pulse is remarkably regular in rate and rhythm and is often around 60 to 70 per minute in adults and averages about 135 in children (age 2-6 years). Cardiac irregularity is very unusual and vagal depression of the pulse rate or blood pressure has only occurred in one case, to my knowledge, exclusive of the above cases. This was due to direct pressure with a retractor on the pericardium and ceased when the pressure was released. On the other hand, it would appear that ether sensitizes the heart to vagal effects, probably by a selective myocardial depression. The same effect may occur without ether if there is previous myocardial disease and/or a marked vagotonia. Atropine also, in insufficient or too early dosage, may allow a vagal effect to show. The mild vagal effects in the three Demerol-Mecostrin- $\mathrm{N}_{2} \mathrm{O}$ anaesthetics mentioned above have not been noted in any case where Flaxedil was the relaxant used. Flaxedil has a vagolytic effect and the pulse is ten beats faster per minute on the average (7). Average pulse rates in chldren age 2-6 undergoing various operations are. DemerolFlaxedil- $\mathrm{N}_{2} \mathrm{O}$ anaesthesia, 145 , Demerol-Mecostrin- $\mathrm{N}_{2} \mathrm{O}, 135 ; \mathrm{N}_{2} \mathrm{O}$-ether, 154. The increased pulse rate may be due to the increase in metabolism with ether whereas the non-volatile anaesthetics, especially Demerol, depress the metabolism.

\section{CONCLUSIONS}

Reflex bradycardia and, occasıonally, cardiac arrest may occur during eye muscle operations. This is much more common under ether anaethesia. Bradycardia may also occur during other procedures involving the mouth, pharynx or oesophagus. Cardiac or pulmonary disease may predispose the patient. These effects may be mitigated by adequate timely atropinization, ${ }^{5}$ and less reliance on ether as the. sole anaesthetic. Mecostrin or Flaxedil intravenously or intramuscularly will reduce the incidence and severity of bradycardia also. Morphine or other opium derivatives might well be avoided on account of their vagomimetic action. Demerol has some vagolytic action and is therefore protective. The bradycardias may be terminated by ceasing the stimulation producing them or by intravenous atropine

During eye operations, at least, the pulse or heart must be constantly monitored. It appears that this may also be advisable when drilling teeth under anaesthesia.

\footnotetext{
${ }^{5}$ Hypodermic atropine reaches its peak effect in 20 minutes and is practically inactive at 90 mmutes In practice, giving the child atropine just before leaving the ward for the operating room is very satisfactory. 1 e., "on call" or "on the stretcher." Earlier administration plus some delay in starting the anaesthetic results in poor atropinization.
} 
It is probably wise to have a slow intravenous running also so that atropine may be given intravenously when needed.

Although my experience is limited, I understand that bronchoscopy under general anaesthesia is considered to be a dangerous procedure in small children. On theoretical grounds this is certainly not surprising. Ether anaesthesia, possibly hypoxia, and vago-vagal reflexes all being combined in many cases. I know of one case of severe bradycardia in a child of seven who was having a vaginal examination that necessitated some forceful dilation. The anaesthesia was ether$\mathrm{N}_{2} \mathrm{O}$.

Finally, I feel reasonably certain that hypoxia and/or hypercardia were not the factors in the cases presented here. All the patients received nitrous oxide oxygen $5 / 2$ litres per minute and respirations were assisted or controlled when necessary.

\section{SUMMARY}

Attention is drawn to the rather common occurrence of bradycardia in children undergoing eye or oro-pharyngeal surgery. This incidence is increased by inadequate atropinization, too much reliance on ether as the main anaesthetic agent, and cardiac or pulmonary disease. Demerol, Flaxedıl or Mecostrin have a protective action in this respect.

\section{RÉSUMÉ}

Nous attirons l'attention sur l'observation assez fréquente d'une bradycardie chez les enfants soumis à la chirurgie ophtalmique ou oropharyngée. Cette bradycardie peut précéder l'arrêt cardiaque. Cette observation est plus fréquente si l'atropinisation est insuffisante, si l'on compte trop sur l'agent anesthésique principal et dans les cas de maladies cardiaques ou pulmonaires. Le Demerol, le Flaxedil ou Mécostrin peuvent exercer une protectıon dans ces cironstances.

\section{REFERENCES}

1 Sorenson, John E, \& Gilmore, John E Cardiac Arrest during Strabismus Surgery Am. J Ophth. 41. 748-752 (May, 1956.)

2 Ascriner, B. Concerning a Hitherto Not Yet Described Reflex from the Eye on Circulation and Respiration Disappearance of the Radial Pulse from Pressure on the Globe Wien. kın. Wchnschr. 21 1529-1530 (Oct, 1908).

3 Lyle, D J. Neuro-Ophthalmology, pp 178, 225. Second edition Springfield, Ill : Charles C. Thomas (1954).

4 Rein, L. C., Stepienson, H E., Jr, \& Hinton, J W. Cardiac Arrest Arch. Surg. 64 409-420 (April, 1952).

5 Howland, William S, \& Papper, E. M. Circulatory Changes durng Anaesthesia for Neurosurgical Operations. Anesthesiology 13: 343-353 (July, 1952).

6 Walton, F. A. Nitrous Oxide-Demerol-Mecostrin Anaesthesia. Proc. Canad. Anaesth. Soc 2: 119 (1953)

7. Walton, F. A. Flaxedıl, a New Curarizing Agent. Canad. M. A. J. 123-129, (Aug., 1950) 